\title{
Histo-pathological pattern of endometrial biopsy in females with abnormal uterine bleeding: a retrospective study in tertiary care hospital of Haryana
}

\author{
Gagan Lata ${ }^{1}$, Susmita Sharma ${ }^{1}$, Sukhbir Pal Kaur ${ }^{1 *}$, Sandhya Panjeta Gulia²
}

\begin{abstract}
${ }^{1}$ Department of Obstetrics and Gynecology, ${ }^{2}$ Department of Pathology, Adesh Medical College and Hospital, Mohri, Shahbad, Kurukshetra, Haryana, India
\end{abstract}

Received: 14 July 2020

Revised: 06 September 2020

Accepted: 08 September 2020

\author{
*Correspondence: \\ Dr. Sukhbir Pal Kaur, \\ E-mail: drsukhbir@hotmail.com
}

Copyright: (C) the author(s), publisher and licensee Medip Academy. This is an open-access article distributed under the terms of the Creative Commons Attribution Non-Commercial License, which permits unrestricted non-commercial use, distribution, and reproduction in any medium, provided the original work is properly cited.

\begin{abstract}
Background: This study aimed to know the various histo-pathological patterns of endometrial biopsy and their incidence in patients of AUB.

Methods: Patients in the age group between 21-75 years who had presented with AUB and underwent endometrial biopsy from $1^{\text {st }}$ January 2017 to $31^{\text {st }}$ December 2019 were included. The endometrial biopsy specimens which were already taken from patients with AUB were scrutinized for histopathological pattern. Various patterns of histopathology of endometrial biopsy were noted and studied.

Results: Most common age group which was affected was between 36-40 years. The endometrial biopsies and curetting's on histopathology revealed various patterns ranging from normal endometrium to malignancy. Patterns of normal cyclical endometrium (proliferative and secretory phases) were the most common patterns.

Conclusions: Evaluation of women with AUB is important around the perimenopausal age group to detect any atypical and malignant changes and intervene early. Histopathological examination in correlation to radiological findings remain the standard procedures for diagnosis.
\end{abstract}

Keywords: AUB, Endometrial biopsy, Malignancy

\section{INTRODUCTION}

Abnormal uterine bleeding (AUB) is defined as bleeding from the uterine corpus that is abnormal in regularity, volume, frequency, or duration and occurs in the absence of pregnancy. A normal menstrual cycle has a frequency of 24 to 38 days, lasts 7 to 9 days, with 5 to 80 millilitres of blood loss. Variations in any of these 4 parameters constitute abnormal uterine bleeding. ${ }^{1}$ Abnormal uterine bleeding can be acute and chronic. Acute AUB is excessive bleeding which requires immediate intervention to prevent further blood loss. Acute AUB can occur on its own or superimposed on chronic AUB, which refers to irregularities in menstrual bleeding for most of the previous 6 months. ${ }^{2}$ Complications of chronic abnormal uterine bleeding can include anemia, infertility, and endometrial cancer. With acute abnormal uterine bleeding, severe anemia, hypotension, shock, and even death may result if prompt treatment and supportive care is not initiated.

The classification system for etiologies has been approved by the International Federation of Gynecology and Obstetrics and supported by the American College of Obstetricians and Gynecologists. ${ }^{3}$ According to this system these are classified as "related to uterine structural abnormalities" and "unrelated to uterine structural abnormalities" and categorized as PALMCOEIN: polyp, adenomyosis, leiomyoma, malignancy 
and hyperplasia, coagulopathy, ovulatory dysfunction, endometrial, iatrogenic, and not otherwise classified. These descriptions apply to chronic, non gestational AUB. AUB associated with the use of exogenous gonadal steroids, intrauterine systems or devices, or other systemic or local agents is classified as "iatrogenic". AUB not otherwise classified contains etiologies that are rare, and include arteriovenous malformations (AVMs), myometrial hyperplasia, and endometritis. ${ }^{3}$

The prevalence of abnormal uterine bleeding among reproductive-aged women internationally is estimated to be between $3 \%$ and $30 \%$, with a higher incidence occurring around menarche and perimenopause. Many studies consider heavy menstrual bleeding (HMB), but when irregular and intermenstrual bleeding are taken into consideration, the prevalence rises to $35 \%$ or greater. ${ }^{3}$ In India, the reported prevalence of AUB is around $17.9 \%$ according to Sharma et al study. ${ }^{4}$

Progesterone levels fall at the end of the menstrual cycle, leading to enzyme breakdown of the functionalis layer of the endometrium. This breakdown leads to blood loss and sloughing which causes menstruation. Functioning platelets and thrombin, and vasoconstriction of the arteries to the endometrium control blood loss. Any derangement in the structure of the uterus (such as leiomyoma, polyps, adenomyosis, malignancy or hyperplasia), derangements to the clotting pathways (coagulopathies or iatrogenically), or disruption of the hypothalamic-pituitary-ovarian axis (through ovulatory/endocrine disorders or iatrogenically) can affect menstruation and lead to abnormal uterine bleeding. ${ }^{5}$ The main goal of evaluation and treatment of chronic AUB is to rule out serious conditions such as malignancy and to improve the patient's quality of life, keeping in mind the fertility goals and other comorbid medical conditions that may impact treatment or symptoms. Endometrial biopsy is one of the simplest and safest method of evaluation of AUB. AUB has great variation in the endometrial patterns and its management entirely depends upon the type of endometrium. Thus, histopathological study of endometrium plays an important role in its treatment. ${ }^{6}$

This study aims to know the various histo-pathological patterns of endometrial biopsy and their incidence in patients of AUB.

\section{METHODS}

This was a retrospective study conducted at Department of Obstetrics and Gynaecology Adesh Medical College and Hospital, Mohri.

\section{Inclusion criteria}

Patients in the age group between 21-75 years who had presented with AUB and underwent endometrial biopsy from $1^{\text {st }}$ January 2017 to $31^{\text {st }}$ December 2019 were included.

\section{Exclusion criteria}

Patients with a gestational cause and pregnancy-related complications were excluded.

The endometrial biopsy specimens which were already taken from patients with AUB were scrutinized for histopathological pattern. Various patterns of histopathology of endometrial biopsy were noted and studied. Specimens with no endometrial tissue or only minimal tissue or breakdown of tissue were given a diagnosis of inadequate for evaluation. Ethical clearance was taken from the ethical committee of the institute before commencement of the study. Descriptive statistical analysis has been used to know the various histopathological patterns of endometrial biopsy and their incidence in patients of AUB.

\section{RESULTS}

The present study was conducted for 200 females with AUB whose endometrial biopsy was taken. Maximum number of females were in age group 36-45. Mean age of the patients was 43 years. Age distribution is shown in Table 1.

Table 1: Age distribution.

\begin{tabular}{|lll|}
\hline $\begin{array}{l}\text { Age distribution } \\
\text { (Years) }\end{array}$ & No. of patients & Percentage \\
\hline $\mathbf{2 1 - 2 5}$ & 8 & 4 \\
\hline $\mathbf{2 6 - 3 0}$ & 14 & 7 \\
\hline $\mathbf{3 1 - 3 5}$ & 22 & 11 \\
\hline $\mathbf{3 6 - 4 0}$ & 48 & 24 \\
\hline $\mathbf{4 1 - 4 5}$ & 34 & 17 \\
\hline $\mathbf{4 6 - 5 0}$ & 27 & 13.5 \\
\hline $\mathbf{5 1 - 5 5}$ & 14 & 7 \\
\hline $\mathbf{5 6 - 6 0}$ & 20 & 10 \\
\hline $\mathbf{6 1 - 6 5}$ & 8 & 4 \\
\hline $\mathbf{6 6 - 7 0}$ & 2 & 1 \\
\hline $\mathbf{7 1 - 7 5}$ & 3 & 1.5 \\
\hline
\end{tabular}

Patterns of normal cyclical endometrium (proliferative and secretory phases) were the most common and seen in $30 \%$ and $19 \%$ cases respectively among cases presenting with AUB. As shown in Table 2, there is overlapping of pathological results of proliferative and secretory endometrium also. Disordered proliferative pattern which lies at one end of the spectrum of proliferative lesions of the endometrium and includes carcinoma at the other end with intervening stages of hyperplasias was seen in 19 $(9.5 \%)$ females.

As shown in Table 2, there were 35 (17.5\%) cases whose pathological diagnosis came out to be cervical polyp who presented with AUB. Histopathological diagnosis of ectocervical and endocervical polyps was made. 
Table 2: Histo-pathological pattern.

Histo-pathological pattern

a) Proliferative endometrium

b) Proliferative endometrium

c) Disordered proliferative endometrium

d) Proliferative endometrium with endometritis

e) Proliferative endometrium with benign endocervical polyp

f) Proliferative endometrium with cervicitis

g) Proliferative endometrium with haemorrhage

h) Proliferative endometrium with extensive breakdown changes

Secretory endometrium

Secretory endometrium

Early Secretory endometrium

Late secretory endometrium

Late secretory endometrium with breakdown changes

Secretory with chronic cervicitis

Proliferative and secretory with stromal and glandular breakdown

Cervical polyp

Cervical polyp

Benign ectocervical polyp

Benign endocervical polyp

Cervical polyp wth microglandular hyperplasia

Leiomyomatous polyp cervix

Leiomyomatous polyp with secretory endometrium

Ulcerated endocervical polyp with secretory endometrium

Hormone effect

Hormone effect

Hormone effect with endometritis acute on chronic

Hormone effect with docervical polyp

Inadequate for evaluation

Insufficient tissue

Extensive breakdown

Endometrial hyperplasia

Hyperplasia without atypia

Hyperplasia without atypia with cervicitis

Endometrial polyp

Endometrial polyp

Benign endometrial polyp with secretory endometrium

Endometrial polyp with endometrial hyperplasia

Endometrial cancer

Mild dysplasia with secretory endometrium

Moderate dysplasia with secretory endometrium

Cervical cancer

Cervicitis

Acute on chronic cervicitis

Chronic cervicitis

Chronic cervicitis with mild dysplasia

Menstrual phase endometrium

Atrophic endometrium

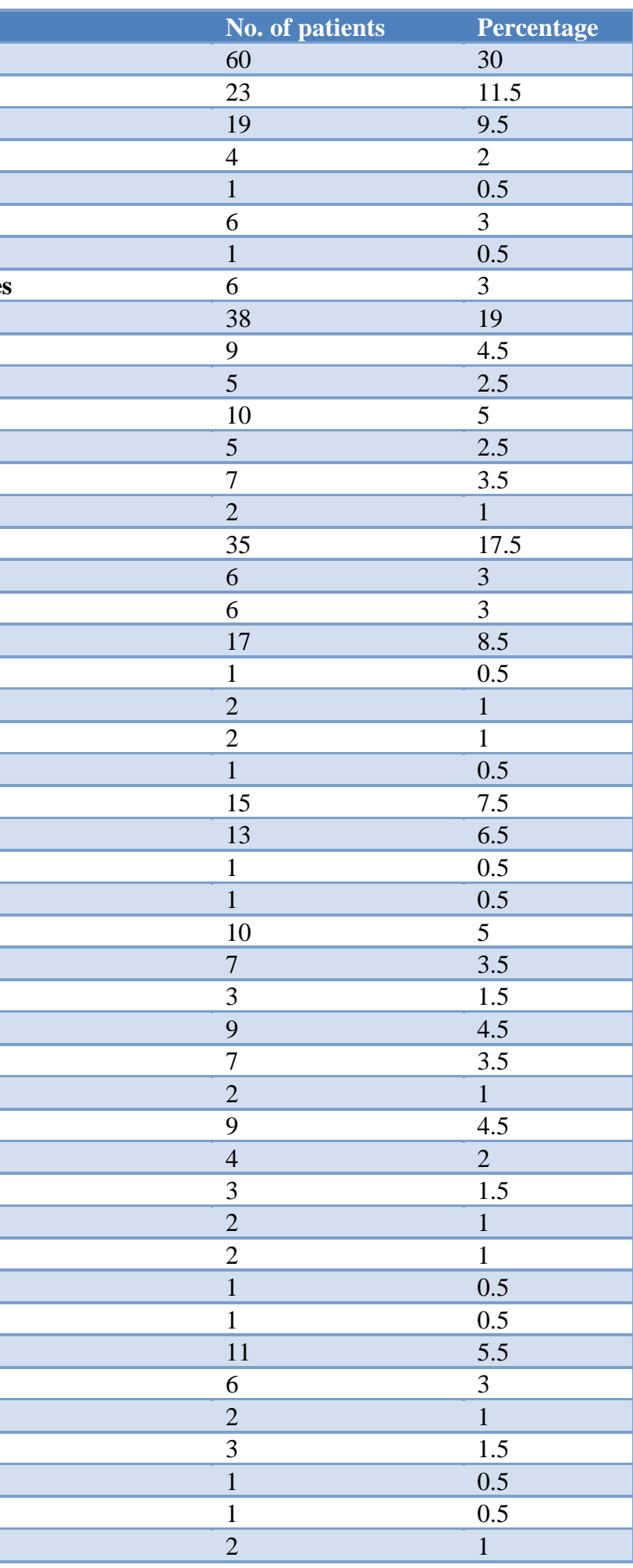

There were $15(7.5 \%)$ females who showed hormonal effect with unusual, non-cyclical appearance of the endometrium. There were $5 \%$ patients whose samples were labelled as inadequate for evaluation.
Nine cases of endometrial hyperplasia were in age group of 40-65 years. All cases of endometrial hyperplasia were without atypia. Most of the cases of endometrial polyp were found in the age group of 30-55 years. 
The malignant conditions observed in this study included 2 cases of endometrial carcinoma and 11 cases of carcinoma of the cervix. Among two cases of endometrial carcinoma which were seen during the study period, the oldest was a 63-year-old woman while the youngest was 54 years old. They both presented with postmenopausal bleeding. One was endometrial carcinoma with squamous differentiation while other was adenocarcinoma with moderate differentiation.

Atrophic endometrium was seen in only 2 patients in this study and presented as postmenopausal bleeding.

There were few cases of AUB who underwent endometrial biopsy and cervical biopsy in same sitting. For those, results came out to be mild dysplasia with secretory endometrium, HSIL with secretory endometrium, and cervicitis as shown in the Table 2.

\section{DISCUSSION}

Abnormal uterine bleeding is one of the most frequently encountered complaints in gynaecology. The diagnosis is mostly based on patient's symptoms and clinical findings supported by pelvic ultrasound in most of the cases. ${ }^{7}$

Dilatation and curettage is to be a diagnostic as well as a therapeutic procedure for these patients. The sensitivity of endometrial biopsy for detection of endometrial abnormalities is very high $96 \% .^{8}$ Endometrial cancer, the most frequent gynaecologic malignancy in the developing world, which develops through preliminary stages of endometrial hyperplasia, which can be very well picked up even in small endometrial biopsies. Thus, correct diagnosis whether benign, premalignant and malignant, help the gynaecologist to decide appropriate therapeutic strategy.

The commonest age group presenting with heavy menstrual bleeding in our study was 35-50 years. A similar incidence was reported by Yusuf et al, Muzaffar et al, and Saraswathy et al. ${ }^{7,9,10}$ The reason for increased incidence of abnormal uterine bleeding in this age group (35-50 years) may be due to the fact that as women approach menopause, cycles shorten and often become intermittently anovulatory due to a decline in the number of ovarian follicles and the estradiol level. ${ }^{10}$

In this study, proliferative (30\%) and secretory (19\%) endometrium were the most common histopathological patterns. Similar observation was made in a study by Abdullah et al Saraswathy et al, and Amruta Padhye et al. ${ }^{10-12}$ In anovulatory cycle, bleeding is due to lack of progesterone possibly non-development of corpus luteum, but in ovulatory cycle, it includes luteal phase defects and irregular shedding, due to persistence corpus luteum, leading to prolonged progesterone level. The bleeding in secretory phase is characterized by regular episodes of heavy menstrual blood loss. The main defect is in the control of processes regulating the volume of blood lost during the menstrual breakdown of endometrium. ${ }^{13}$

Disordered proliferative endometrium differs from the normal proliferative endometrium in the absence of uniform glandular development but is not abnormal enough to be considered hyperplastic. It is an exaggeration of the normal proliferative phase without significant increase in the overall ratio of glands to stroma and is due to persistent oestrogen stimulation. ${ }^{14}$ The disordered proliferative endometrium resembles normal proliferative tissue in consisting of glands lined by cytologically bland, pseudostratified, proliferative, mitotically active epithelium and in having a normal ratio of glands to stroma. Diagnosing the patients at the earliest stage of this spectrum will be of definitive help to the practicing gynaecologists to prevent the disease progression. In this study $9.5 \%$ cases were seen while literature reveals $5.7 \%$ to $20.54 \%$ cases. ${ }^{10,11,15,16}$

Hormone preparations containing both oestrogen and progestogen (most modern hormone replacement treatment regimens), characteristically result in a weak or poorly developed secretory endometrium. ${ }^{17,18}$ Whereas with other preparations the endometrium is atrophic. Progestogen-only compounds result in a characteristic morphological appearance with atrophic or weak secretory-type glands set in an expanded stroma that exhibits varying degrees of pseudo decidualisation. This pseudo decidualisation is often most prominent just beneath the surface glands and is usually accompanied by an inflammatory cell infiltrate, largely comprising natural killer cells. Effect of exogenous hormones was seen in 15 $(7.5 \%)$ cases. Similar incidence $(7.7 \%)$ was reported by Sajitha et al. ${ }^{19}$ In this pattern, the endometrium shows a combination of inactive glands, abortive secretions, decidual reaction, and thin blood vessels. This may be attributed to the fact that, increased numbers of patients in this age usually seek for early medical management for bleeding.

Endometrial hyperplasia is a precursor of endometrial cancer. It is more commonly seen during the perimenopausal period. ${ }^{20}$ As endometrial hyperplasia is a precursor of endometrial cancer, with overall risk of progression to cancer being $5-10 \%$, its identification is important in peri and postmenopausal patients presenting with AUB. In this study, hyperplasia was seen in 9 $(4.5 \%)$ cases. All were cases of hyperplasia without atypia. Almost similar incidence was reported $(5.79 \%)$ by Jairajpuri et al. ${ }^{16}$ The 2014 revised WHO classification simply separates endometrial hyperplasia into two groups based upon the presence or absence of cytological atypia, i.e. (i) hyperplasia without atypia and (ii) atypical hyperplasia; the complexity of architecture is no longer part of the classification. ${ }^{1}$ The widely adopted 1994 WHO classification of endometrial hyperplasia was based upon both the complexity of the glandular architecture and the presence of nuclear atypia. It comprised four categories: (i) simple hyperplasia, (ii) complex 
hyperplasia, (iii) simple hyperplasia with atypia and (iv) complex hyperplasia with atypia. ${ }^{21}$

The occurrence of polyps in cases of AUB was found to be $4.5 \%$ which is comparable to $5.12 \%$ in Sajitha et al study. ${ }^{19}$

Endometrial carcinoma can occur as a, result of excess estrogenic stimulation and developing against a background of endometrial hyperplasia or de novo combined with insufficient progesterone levels. Endometrioid endometrial carcinoma is the most common form of endometrial cancer. In our study two cases $(1 \%)$ of endometrial cancer were seen. Both the patients presented with post-menopausal bleeding. This is in concordance with literature where endometrial carcinoma was also commonly seen in the postmenopausal age group. ${ }^{10,11}$ Nulliparity, increased body mass index, and chronic anovulation have been implicated as risk factors for endometrial carcinoma.

Atrophic endometrium was seen in 2 cases (1\%) at age of $>60$ years almost similar to other reports of $2.2 \% .^{22}$ Atrophy of endometrium occurs as consequence of the prolonged absence of any endogenous or exogenous estrogenic stimulation. The thin atrophic endometrium is susceptible to trivial trauma, which may be responsible for postmenopausal bleeding.

Menstrual pattern was seen in $1.28 \%$ cases in Sajitha study as compared to $0.5 \%$ in our study. ${ }^{19}$

Endometrial specimens were inadequate for evaluation in $5 \%$ cases which is comparable to $5.96 \%$ cases in Vaidya et al study. ${ }^{23}$ Those endometrial specimens labelled unsatisfactory for scanty or minimal amount of fragmented glands and stromal tissue and large areas of haemorrhage. Limited literature is available on the criteria for adequate and inadequate endometrial specimen.

\section{CONCLUSION}

Evaluation of women with AUB is important around the perimenopausal age group to detect any atypical and malignant changes and intervene early. Histopathological examination in correlation to radiological findings remain the standard procedures for diagnosis. In our study we found that most common age group which was affected was between 36-40 years. The endometrial biopsies and curettings on histopathology revealed various patterns ranging from normal endometrium to malignancy. Majority of the patients with AUB presented with normal cyclic endometrium. Although, the incidence of hyperplasia and malignancy is low in our study but those few cases are also important to diagnose. The incidence of endometrial hyperplasia and endometrial carcinoma were more common in the perimenopausal and postmenopausal women. Hence, histopathological evaluation of the endometrium is specially recommended in women of these age groups presenting with AUB, to rule out possibility of preneoplastic condition or malignancy.

Funding: No funding sources

Conflict of interest: None declared

Ethical approval: The study was approved by the Institutional Ethics Committee

\section{REFERENCES}

1. Fraser IS, Critchley HO, Munro MG, Broder M. Can we achieve international agreement on terminologies and definitions used to describe abnormalities of menstrual bleeding? Hum Reprod. 2007;22(3):63543.

2. American College of Obstetricians and Gynecologists. ACOG committee opinion no. 557: Management of acute abnormal uterine bleeding in nonpregnant reproductive-aged women. Obstet Gynecol. 2013;121(4):891-6.

3. Munro MG, Critchley HOD, Fraser IS, FIGO Menstrual Disorders Committee. The two FIGO systems for normal and abnormal uterine bleeding symptoms and classification of causes of abnormal uterine bleeding in the reproductive years: 2018 revisions. Int J Gynaecol Obstet. 2018;143(3):393408.

4. Sharma A, Dogra Y. Trends of AUB in tertiary centre of Shimla hills. J Midlife Health. 2013;4:67-8.

5. Whitaker L, Critchley HO. Abnormal uterine bleeding. Best Pract Res Clin Obstet Gynaecol. 2016;34:54-65.

6. Patil R, Patil RK, Andola SK, Laheru V, Mallikarjuna B. Histopathological spectrum of endometrium in dysfunctional uterine bleeding. Int $\mathbf{J}$ Biol Med Res. 2013;4:2798-801.

7. Yusuf NW, Nadeem R, Yusuf AW. Dysfunctional uterine bleeding. A retrospective clinic pathological study over 2 years. Pak J Obstet Gynaecol. 1996;9:27-30.

8. Ghani NA, Abdulrazak AA, Abdullah EM. Abnormal uterine bleeding: A histopathological study. J Pathol.2014;3(2):068-070.

9. Muzaffar M, Akhtar KA, Yasmin S, Rehman M, Iqbak W, Khan MA. Menstrual Irregularities with excessive blood logs: A clinicopathological correlation. J Pak Med Association. 2005;55:486-9.

10. Saraswathi D, Thanka J, Rao S, Aarthi RK, Vijayaraghavan J, Kumar PV. Study of endometrial pathology in abnormal uterine bleeding. J Obstet Gynecol India. 2011;61(4):426-30.

11. Abdullah LS, Bondagji NS. Histopathological pattern of endometrial sampling performed for abnormal uterine bleeding. Bahrain Med Bull. 2011;33(4):195-8.

12. Padhye A, Kaul U, Dhar R. Histopathology of endometrial biopsies in cases of abnormal uterine bleeding- a four year study. J Med Sci Clin Res. 2017;5(05):21597-9. 
13. Livingstone M, Fraser IS. Mechanisms of abnormal uterine bleeding. Hum Reprod Update. 2002;8:60-7.

14. Mazur MT, Kurman RJ. Normal endometrium and infertility evaluation. In: Mazur MT, Kurman RJ, eds. Diagnosis of endometrial biopsies and curettings: A practical approach. 2nd ed. New York: Springer Verlag; 2005:7-33.

15. Gon S, Kundu T, Mallick D, Ghosh G. A study on histopathological patterns of endometrium in different types of abnormal uterine bleeding among peri and postmenopausal women. IOSR J Dent Med Sci. 2016;15(09):106-11.

16. Jairajpuri ZS, Rana S, Jetley S. Atypical uterine bleeding-Histopathological audit of endometrium. A study of 638 cases. Al Ameen J Med Sci. 2013;6(1):21-8.

17. Feeley KM, Wells M. Hormone replacement therapy and the endometrium. J Clin Pathol. 2001;54:435-40.

18. Piegsa K, Calder A, Davis JA, McKay-Hart D, Wells M, Bryden F. Endometrial status in post-menopausal women on long-term continuous combined hormone replacement therapy (Kliofem ${ }^{\circledR}$ ) a comparative study of endometrial biopsy, outpatient hysteroscopy and transvaginal ultrasound. Eur J Obstet Gynecol Reprod Biol. 1997;72(2):175-80.
19. Sajitha K, Padma SK, Shetty KJ, Prasad KHL, Permi HS, Hegde P. Study of histopathological patterns of endometrium inabnormal uterine bleeding. Chris Med J Health Res. 2014;1:76-81.

20. Bindroo S, Garg M, Kaur T. Histopathological spectrum of endometrium in abnormal uterine bleeding. Int J Reprod Contracept Obstet Gynecol. 2018;7:3633-7.

21. Kurman RJ, Carcangiu ML, Herrington CS, Young $\mathrm{RH}$, editors. WHO Classification of Tumours of Female Reproductive Organs. 4th ed. [Lyon]: IARC; 2014.

22. Puvitha RD, Elavarasan T, Shruthi MS, Shylaja S. Histopathological study of endometrium in abnormal uterine bleeding: an experience in a tertiary care centre of rural South India. NJBMS. 2017;8:32-8.

23. Vaidya S, Lakhey M, Vaidya SA, Sharma PK, Hirachand S, Lama S, et al. Histopathological pattern of abnormal uterine bleeding in endometrial biopsies. Nepal Med Coll J. 2013;15(1):74-7.

Cite this article as: Lata G, Sharma S, Kaur SP, Gulia SP. Histo-pathological pattern of endometrial biopsy in females with abnormal uterine bleeding: a retrospective study in tertiary care hospital of Haryana. Int J Reprod Contracept Obstet Gynecol 2020;9:4068-73. 